\title{
FECUNDAÇÃO E CLIVAGEM APÓS A ATIVAÇÃO DA PROTEÍNA QUINASE C DURANTE A MATURAÇÃO DE OÓCITOS BOVINOS ${ }^{1}$
}

\author{
FERTILIZATION AND CLEAVAGE AFTER PROTEIN KINASE \\ C ACTIVATION DURING BOVINE OOCYTE MATURATION
}

\author{
Rafael Gianella Mondadori ${ }^{2}$ Paulo Bayard Dias Gonçalves ${ }^{3}$ Jairo Pereira Neves ${ }^{4}$ \\ Luis Fabiano Santos da Costa ${ }^{2}$ Marcelo Marcos Montagner ${ }^{2}$ \\ Silvia Ferreira Carámbula ${ }^{2}$ Ederson Bisognin Bortolotto ${ }^{2}$
}

RESUMO

A formação de pró-núcleos, clivagem e perfil protéi co foram avaliados após a ativação da proteína quinase $C(P Q-$ C) durante a maturação de complexos cumulus-oócito (CCOs) bovinos. Visando a determinar estes efeitos da PO-C, $1936 \mathrm{CCOs}$ foram distribuídos aleatoriamente em 4 tratamentos, sendo maturados na presença de PMA (100nM phorbol 12-myristate 13-acetate, ativador da PQ-C), de $4 \alpha-P D D$ (100nM de $4 \alpha$ phorbol 12,13-didecanoetate, forbol éster que não ativa a $P Q-C$; controle forbol éster), de SVE (10\% de soro de vaca em estro, controle positivo) e de um controle negativo constituído pelo meio de maturação básico para os demais tratamentos, com exceção do SVE, onde não foi adicionado o álcool polivinílico (PVA). Os CCOs foram mantidos na presença de PMA por $1,4 e$ 7 horas, sendo após, transferidos para o meio básico de maturação até que se completassem 24 horas de cultivo. A estimulação da $P Q-C$, por esses períodos, não alterou a formação de prónúcleos, porém, diminuiu a percentagem de clivagem dos zigotos. Os resultados do grupo $4 \alpha-P D D$ comprovam que as alterações ocorridas no grupo PMA são devido à ativação da $P Q-C$ e não ação direta do forbol éster na célula. A análise da composição protéica demonstrou uma banda de proteína adicional no grupo SVE ao redor de 74 kilo Daltons (kDa). Os resultados desse estudo, quando associados aos dados preliminares de Western blot, indicam a importância da $P Q-C$ na regulação da maturação, fecundação e clivagem de embriões bovinos.

Palavras-chave: proteína quinase-C, eletroforese, maturação de oócitos, bovino.

\section{SUMMARY}

In the present study the pronucleus formation, cleavage and protein profile after protein kinase $C(P K-C)$ acti-

\begin{abstract}
vation were evaluated during bovine oocyte maturation. A total number of 1936 bovine cumulus-oocyte complexes (COCs) were randomly distributed in 4 treatments, and matured with PMA (100nM phorbol 12-myristate 13-acetate, PK-C activator), $4 \alpha$ PDD (100nM de $4 \alpha$-phorbol 12,13-didecanoetate, phobol ester that do not bind on PK-C, phorbol ester control), ECS (10\% of estrus cow serum, positive control) and in a negative control (basic maturation media for all treatments, except on ECS group where the polyvinyl alcohol was not added). The COCs were kept in presence of PMA for 1, 4 or 7 hours and then transferred to basic maturation media until the 24 hours maturation period was completed. The PK-C stimulation in these periods did not alter the pronucleus formation but caused a decrease in the zygotes cleavage rate. The $4 \alpha-P D D$ group results showed that the alterations in PMA group were caused by $P K-C$ activation and not by direct phorbol ester action on the cell. The protein composition analysis showed an additional protein band on ECS group around 74 kilo Daltons $(k D a)$. Altogether, these results with the preliminary Western Blot analysis, indicate an important role of $P K-C$ on bovine oocyte maturation, fertilization and embryo cleavage.
\end{abstract}

Key words: protein kinase-C, SDS-PAGE, oocyte maturation, bovine.

\section{INTRODUÇÃO}

Com o conhecimento dos mecanismos envolvidos na regulação da maturação de oócitos e desenvolvimento embrionário precoce, os sistemas in vitro poderão ser aperfeiçoados e os índices de produção de embriões podem ser incrementados significativamente, o que representaria um grande

\footnotetext{
${ }^{1}$ Trabalho implementado com suporte financeiro da FAPERGS.

${ }^{2}$ Médico Veterinário, Programa de Pós-graduação em Medicina Veterinária, área de concentração em Fisiopatologia da Reprodução.

${ }^{3}$ Ph.D, Professor Titular, Departamento de Clínica de Grandes Animais, Centro de Ciências Rurais (CCR), Universidade Federal de Santa Maria (UFSM), 97105-900, Santa Maria, RS. E-mail: bayard@lince.hcv.ufsm.br. Autor para correspondência.

${ }^{4}$ Doutor, Professor Titular, Departamento de Clínica de Grandes Animais, CCR, UFSM.
} 
avanço, tanto para técnicas que exigem a produção de embriões em larga escala, como para a aplicação em um programa de melhoramento genético associado à técnica de punção folicular in vivo.

Há evidências que a maturação de oócitos é dependente de hormônios esteróides e de sinais químicos determinados por hormônios protéicos e fatores de crescimento. Esses sinais ativam receptores presentes na membrana citoplasmática, estimulando a formação intracelular de segundos mensageiros (BERRIDGE, 1985) como diacilglicerol (DG), inositol trifosfato $\left(\mathrm{IP}_{3}\right)$ e $\mathrm{Ca}^{2+}$, os quais, por ativação de quinases e fosfatases estão envolvidos na transmissão do sinal da membrana celular ao núcleo (BAE \& CHANNING, 1985; HOMA, 1991; HOMA et al., 1991; KAUFMAN \& HOMA, 1993). Também, os processos meióticos e mitóticos, que ocorrem durante a transição de oócito competente a zigoto, são regulados por fosforilação e desfosforilação de proteínas, envolvendo diferentes quinases e fosfatases (MILOVANOV \& SIRARD, 1994; LEVESQUE \& SIRARD, 1995).

$\mathrm{Na}$ reprodução de bovinos, a rota bioquímica da PQ-C está envolvida em processos como a maturação de oócitos (GONÇALVES et $\boldsymbol{a l}$., 1994; ROSEHELLEKANT \& BAVISTER, 1996), o desenvolvimento embrionário precoce (MINAMI, 1996) e a transição de oócito maturo a zigoto (COLONNA et $\boldsymbol{a l}$., 1997). A ativação da PQ-C, que exerce um importante papel na regulação da maturação in vitro de oócitos, vem sendo estudada em diferentes espécies como camundongos (GONÇALVES \& GRAVES, 1992), suínos (SCHOENBECK $\boldsymbol{e t}$ al., 1993) e bovinos (ROSEHELLEKANT \& BAVISTER, 1996). Essas pesquisas também demonstraram que os resultados obtidos revelam variação entre as espécies estudadas. Durante o processo de maturação de oócitos bovinos, a ativação da PQ-C estimula o rompimento da vesícula germinativa (RVG), alcançando índices de 93,9\% após 7 horas de maturação em presença do ativador PMA, enquanto no controle, sem PMA, esse índice foi de 59,4\% (VIGNOLA, 1995). O presente trabalho foi desenvolvido visando a elucidar quais os efeitos da ativação da PQ-C durante a maturação de CCOs sobre a posterior formação de pró-núcleos e clivagem em bovinos.

\section{MATERIAL E MÉTODOS}

Os 1936 oócitos, utilizados no trabalho, foram obtidos de folículos com diâmetro entre 2 e $8 \mathrm{~mm}$ e completamente rodeados por, no mínimo, 3 camadas de células do cumulus e com ooplasma homogêneo de coloração marrom. Os CCOs foram aleatoriamente distribuídos em grupos de 25 e maturados em gotas de $200 \mu \mathrm{l}$ de TCM-199 modificado com adição de $25 \mathrm{nM}$ de HEPES, gonadotrofinas $(5 \mu \mathrm{g} / \mathrm{ml}$ de $\mathrm{LH}$ e $0,5 \mu \mathrm{g} / \mathrm{ml}$ de FSH), $2,2 \mathrm{mg} / \mathrm{ml} \mathrm{de}$ bicarbonato de sódio, $0,2 \mathrm{mM}$ de piruvato de sódio e $1 \mathrm{mg} / \mathrm{ml}$ de PVA, em estufa a $39^{\circ} \mathrm{C}$ com umidade saturada e atmosfera de $5 \%$ de $\mathrm{CO}_{2}$ em ar. Os CCOs foram maturados em 4 diferentes grupos, tendo como base o TCM-199, ao qual foi adicionado: 100 nM de PMA (tratamento), $100 \mathrm{nM}$ de $4 \alpha$-PDD (controle do forbol éster). No controle positivo, o PVA foi substituído por $10 \%$ de SVE e, como controle negativo foi utilizado apenas o meio básico TCM-199 modificado, porém, cada experimento foi realizado com partidas distintas de SVE. O tempo de maturação dos oócitos foi de 24 horas, variando o tempo de exposição ao PMA por 1 (PMA-1h), 4(PMA-4h) e 7 (PMA-7h) horas. Assim sendo, terminado o período de contato com o PMA, os CCOs foram lavados em 3 gotas, contendo o meio básico e mantidos nesse meio até que se completasse o período de maturação.

Antes do início dos experimentos, e para que fosse avaliada a taxa de ativação partenogenética, 127 CCOs maturados nos diferentes meios foram co-incubados com espermatozóides que passaram por gradiente de Percoll, sendo mortos em água tridestilada e, posteriormente, lavados 3 vezes em FERT-TALP (LEIBFRIED-RUTLEDGE $\boldsymbol{e} \boldsymbol{a} \boldsymbol{a l}$, 1989). A concentração final no meio de fecundação foi de $2 \times 10^{6}$ espermatozóides $/ \mathrm{ml}$. A incubação foi realizada por 18 a 20 horas em gotas de $250 \mu \mathrm{l}$ do meio FERT-TALP. Após este período, as células do cumulus foram retiradas, os oócitos foram transferidos para meio de desenvolvimento embrionário (KSOM; LIU \& FOOTE, 1994). Após 48h de incubação, foi registrado o número de zigotos que clivaram.

A fecundação foi realizada em FERTTALP com $2 \times 10^{6}$ espermatozóides vivos $/ \mathrm{ml}$, previamente separados por gradiente de Percoll. Terminado o período de fecundação (18 a 20 horas), foi efetuada a retirada das células do cumulus dos zigotos e estes foram transferidos para gotas de $200 \mu \mathrm{l}$ de KSOM. Quando o objetivo era a visualização de pró-núcleos (PN), os zigotos foram mantidos em KSOM até que se completassem 27 horas do início da fecundação, quando foram transferidos para placas com fixador, conforme técnica descrita por VIGNOLA et al. (1994). A taxa de clivagem foi avaliada 24 horas após a transferência para KSOM com monocamada de células epiteliais de oviduto bovino.

O delineamento experimental utilizado foi o de blocos inteiramente casualisados. Os diferentes 
tratamentos foram realizados simultaneamente, sendo que cada réplica foi considerada um bloco. Os resultados em percentagem foram transformados pelo PROC RANK (CONOVER \& IMAN, 1981) no programa estatístico SAS, com a finalidade de aplicação de testes paramétricos para a análise dos resultados. As taxas de partenogênese e poliespermia foram submetidas à análise de qui-quadrado $\left(\chi^{2}\right)$.

Visando à avaliação do perfil protéico, duzentos CCOs por grupo, incluído um grupo de oócitos imaturos, foram submetidos à separação de proteínas por eletroforese (SDS-PAGE), utilizando um gel constituído por $10 \%$ de acrilamida. Após o término da separação protéica, o gel foi submetido à coloração com Azul de Coomassie.

\section{RESULTADOS E DISCUSSÃO}

Prévio ao início dos experimentos, foi comprovado que a ativação da PQ-C durante a maturação do oócitos bovinos não provoca ativação partenogenética. (Tabela 1). Conforme pode ser observado, os índices de partenogênese do sistema apresentam-se bastante baixos, não havendo diferença entre os grupos experimentais utilizados, comprovando que este sistema não afetou os índices de clivagem nos demais experimentos.

Não houve incremento na formação de pró-núcleos quando os oócitos foram maturados por 1, 4 ou 7 horas em presença de PMA. Os grupos PMA-1h, PMA-4h e PMA-7h não apresentaram diferença entre si $(p>0,05)$, mas foram significativamente inferiores ao controle positivo e iguais ao

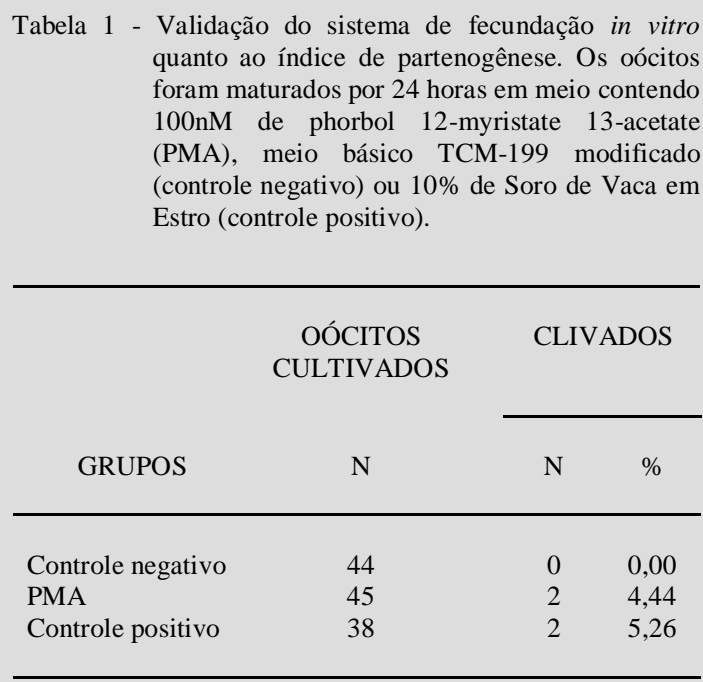

Não há diferença estatística entre os diferentes grupos $(\mathrm{p}>0,05)$ negativo. O controle positivo foi superior aos demais (Figura 1).

Alguns estudos de rotas bioquímicas são realizados com meios de composição desconhecida, ou seja, com a adição de SVE ou BSA que reconhecidamente influem sobre o processo de maturação de oócitos (SIRARD et al., 1988; PARRISH, 1991). Por este motivo, para determinar os requerimentos bioquímicos e fisiológicos que inibem ou estimulam os processos in vitro, é necessário utilizar meios livres de fontes protéicas de composição desconhecida, como foi realizado no presente estudo.

Os experimentos realizados por SCHOENBECK $\boldsymbol{e}$ t al. (1993) e VIGNOLA, (1995) utilizaram ativadores naturais (diacilglicerol, DiC8) e artificiais (PMA) da PQ-C, não sendo constatada diferença de comportamento dos CCOs quando estes dois grupos foram comparados, assim sendo, no presente estudo foi utilizado somente o ativador artificial (PMA), devido a sua facilidade de manipulação. Devido ao PMA ser um ativador artificial da PQ-C e não ser metabolizado com a mesma intensidade que o DG (ALBERTS et al., 1994), a exposição por períodos inferiores a 24 horas poderia provocar incremento na formação de pró-núcleos, o que não foi observado. Esses resultados demonstram que a PQ-C não foi ativada pelo tempo necessário para obtenção de incremento na formação de prónúcleos, como é obtido quando a PQ-C é estimulada por 24 horas (dados não demonstrados).

A PQ-C, quando estimulada após a maturação do oócito, é reconhecidamente um agente de ativação partenogenética de diversas espécies como suínos (SCHOENBECK, et al., 1993), camundongos (COLONNA et al., 1997) e hamsters (GALLICANO

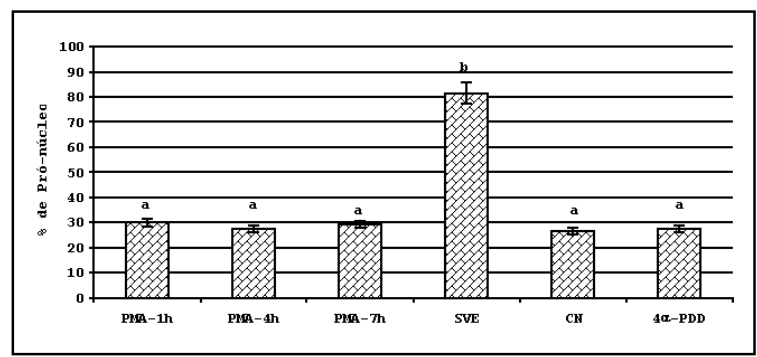

Figura 1 - Efeito da ativação da PQ-C, durante a maturação, por diferentes períodos na formação de pró-núcleos. Os oócitos foram maturados por 24 horas, permanecendo por 1 hora (PMA-1h), 4 horas (PMA-4h) e 7 horas (PMA-7h) em presença de 100 nM de PMA; $10 \%$ de SVE (SVE); controle negativo (CN) e $100 \mathrm{nM}$ de $4 \alpha$ PDD (4 $\alpha$-PDD) e fecundados com $2 \times 10^{6}$ espermatozóides previamente capacitados $/ \mathrm{ml}$. A taxa de formação de pró-núcleos foi acessada 27 horas após a fecundação. Os valores representam o percentual médio de 4 réplicas. Letras diferentes significam diferença $(\mathrm{p}<0,05)$. 
et al., 1993), além de estimular a exocitose de grânulos corticais (CHOI et al. 1994; DUCIBELLA \& LeFEVRE, 1997) o que impossibilitaria a fecundação. Neste estudo, foi determinado que a utilização de $100 \mathrm{nM}$ de PMA durante a maturação de oócitos bovinos não induz a aumento na taxa de partenogênese, validando os resultados de formação de pró-núcleos.

Conforme observado na Figura 2, os grupos controle (positivo, negativo e $4 \alpha$-PDD) não apresentaram diferenças, quanto ao percentual de clivagem ( $p>0,05)$. Por outro lado, os oócitos que permaneceram em contato com PMA, mesmo que por apenas 1 hora, apresentaram prejuízo em sua clivagem, sendo esta significativamente inferior aos grupos controle (FIGURA 2). Também não houve diferença entre PMA-1h, PMA-4h e PMA-7h.

Em camundongos, COLONNA et al. (1997) e GALLICANO et al. (1997) determinaram que a PQ-C é fundamental para a passagem de oócito para zigoto, ou seja, em sua ausência não se obtém clivagem. Conforme os resultados de clivagem e os dados preliminares de Western blot (dados não demonstrados), há evidências que em bovinos ela também é necessária, não havendo, como no caso da maturação nuclear, comportamento oposto entre essas espécies. A inibição da clivagem pode ser devido a mudanças dramáticas na rede de microfilamentos, como observado em outros tipos celulares (TRIFARO $\boldsymbol{e t}$ al., 1992). Conforme observação realizada por VIGNOLA (1995), a adição de SVE ao meio de maturação parece diminuir os efeitos bloqueadores do PMA sobre a clivagem. s grupo controle negativo e o grupo $4 \alpha$-PDD não apresentaram diferença quanto à taxa de clivagem. Isso demonstra

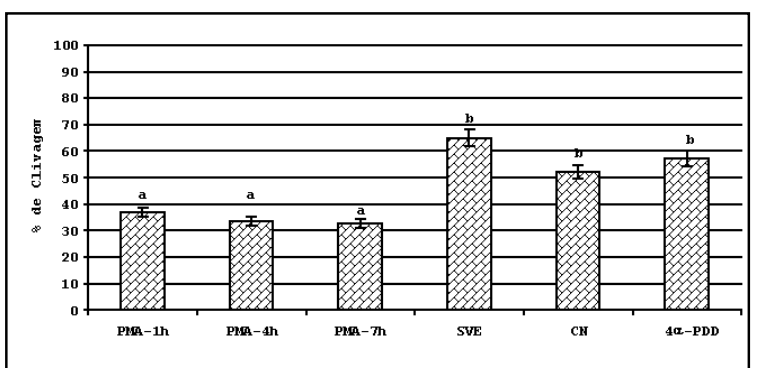

Figura 2 - Efeito da ativação da PQ-C, durante a maturação, por períodos diferentes, na taxa de clivagem. Os oócitos foram maturados por 24 horas, permanecendo por 1 hora (PMA-1h), 4 horas (PMA-4h) e 7 horas (PMA7h) em presença de $100 \mathrm{nM}$ de PMA; $10 \%$ de SVE (SVE); controle negativo (CN) e $100 \mathrm{nM}$ de $4 \alpha-\mathrm{PDD}$ (4 $\alpha$-PDD) e fecundados com $2 \times 10^{6}$ espermatozóides previamente capacitados $/ \mathrm{ml}$. A taxa de clivagem foi acessada 48 horas após a fecundação. Os valores representam o percentual médio de 4 réplicas. Letras diferentes significam diferença $(\mathrm{p}<0,05)$. que o bloqueio da clivagem não ocorre por efeito tóxico do forbol éster na célula, mas sim pela ativação da PQ-C.

Neste experimento, a adição ao meio de maturação de substâncias biologicamente ativas, sem composição definida e com potencial efeito deletério, demonstra a importância da utilização de meios definidos para previsão e uniformização dos resultados, pois, quando a partida de SVE utilizada foi trocada, houve uma mudança brusca nos resultados, de maneira que o grupo controle positivo não diferiu do controle negativo, o que, neste caso em particular, não compromete os resultados, pois a clivagem dos grupos que continham PMA foram inferiores ao controle negativo.

O processo de separação protéica por eletroforese possibilitou visualizar uma banda de proteína adicional, ao redor de $74 \mathrm{kDa}$, nos oócitos maturados em SVE (Figura 3). Dados não demonstrados de Western blot revelaram que essa banda é a PQ-C e está presente em todos os grupos, exceto nos maturados em PMA.

A ausência da banda de 74 kDa e da PQ$\mathrm{C}$ no final do período de maturação de CCOs maturados em meio contendo $100 \mathrm{nM}$ de PMA e sua presença nos demais grupos, inclusive no grupo de oócitos imaturos, sugere que esta tenha sido degradada pelo estímulo do forbol éster. Como a ativação da PQ-C é necessária no momento da clivagem (COLONNA et al., 1997) e, estando esta ausente, torna-se bastante óbvio que, assim como em camun-

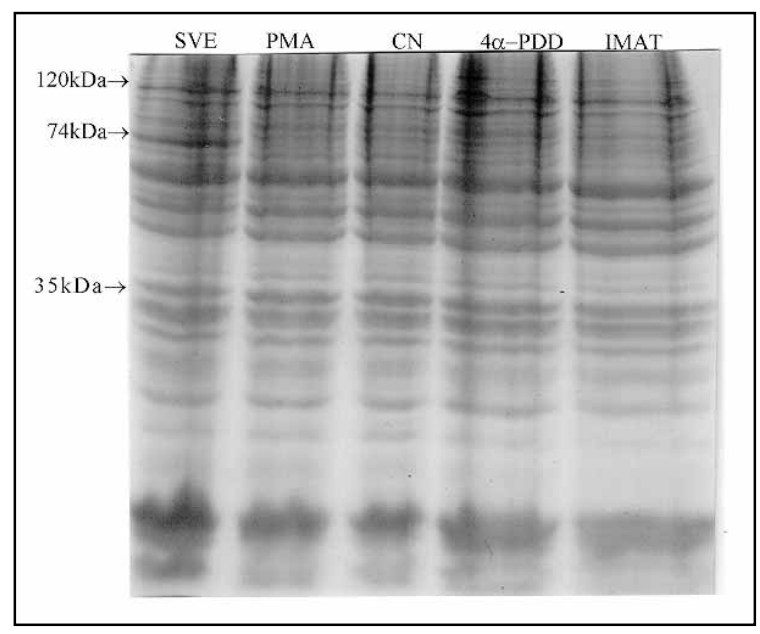

Figura 3 - SDS-PAGE (10\%) de 200 oócitos por raia, maturados nos diferentes meios e corados com Azul de Coomassie. Cada raia corresponde a um grupo: SVE (controle positivo); PMA (100nM por 24 horas); Controle negativo $(\mathrm{CN}) ; 4 \alpha$-PDD (100nM por 24 horas); IMAT (oócitos imaturos). Os diferentes pesos moleculares determinados pelo padrão (SIGMA) estão indicados a esquerda da figura. 
dongos, em bovinos também é necessária a presença de PQ-C no momento da clivagem.

O fator promotor da maturação (MPF) possui papel essencial no RVG em oócitos de diversas espécies, inclusive bovinos (TATEMOTO \& TERADA, 1996). Para ativação do MPF é indispensável fosforilação e desfosforilação protéica, resultando no reinício da meiose e, posteriormente, na primeira divisão mitótica (DEKEL, 1996). Os mecanismos responsáveis pela ativação do MPF em oócitos de mamíferos permanecem desconhecidos, podendo haver o envolvimento da rota bioquímica estimulada neste trabalho.

Como pode ser observado nos resultados obtidos no presente estudo, fica bastante evidente a influência da rota da PQ-C na regulação da maturação de oócitos bovinos e seu reflexo no desenvolvimento embrionário precoce. A estimulação da PQ-C pelos períodos de 1, 4 e 7 horas não estimula a formação de PN e provoca prejuízo na clivagem. Os dados iniciais, que demonstram a ausência de PQ-C no final do período de maturação, permitem concluir sua importância no desenvolvimento embrionário precoce. Assim sendo, os resultados aqui obtidos demonstram a necessidade da continuidade dos estudos desta rota bioquímica em oócitos bovinos.

\section{AGRADECIMENTOS}

Os autores agradecem aos Drs. Eduardo Furtado Flores e Luiz Carlos Kreutz, do Laboratório de Virologia da UFSM pelo auxílio na técnica de eletroforese e pelas importantes contribuições dadas para a realização deste estudo, ao Frigorífico Silva S.A. pela doação dos ovários e a Pecplan-ABS, na pessoa do Dr. Neimar Correia Severo, pela doação do sêmen.

\section{REFERÊNCIAS BIBLIOGRÁFICAS}

ALBERTS, B., BRAY, D., LEWIS, J., et al. Molecular Biology of the Cell. New York: Garland Publishing Inc, 1994, 1218 p.

BAE, I.H., CHANNING, C.P. Effect of calcium-ion on the maturation of cumulus-enclosed pig follicular oocytes isolated from medium-sized graafian-follicles. Biology of Reproduction, v. 33, n. 1, p. 79-87, 1985

BERRIDGE, M.J. The molecular basis of communication within the cell. Scientific American, v. 253, n. 3, p. 142-152, 1985.

CHOI, S.C., YOO, H.J., LEE, S.H. Analysis of cortical granule exocytosis and pronucleus formation in bovine oocytes upon exposure to $\mathrm{Ca}^{2+}$ inophore A23187 and phorbol 12-myristate 13 acetate. Korean Journal of Animal Science, v. 36, n. 2, p. 144-153, 1994

COLONNA, R., TATONE, C., FRANCIONE, A., $\boldsymbol{e}$ t al. Protein kinase $\mathrm{C}$ is required for the disappearance of MPF upon artificial activation in mouse eggs. Molecular Reproduction and Development, v. 48, p. 292-299, 1997.
CONOVER, W.J., IMAN, R.L. Rank transformation as a bridge between parametric and nonparametric statistics. The American Statistician, v. 35, n. 3, 1981.

DEKEL, N. Protein phosphorilation/ dephosphorilation in the meiotic cell cycle of mammalian oocytes. Reviews of Reproduction, v. 1, p. 82-88, 1996.

DUCIBELlA, T., LeFEVRE, L. Study of protein kinase C antagonists on cortical granule exocytosis and cell-cycle resumption in fertilized mouse egg. Molecular Reproduction and Development, v. 46, p. 216-226, 1997.

GALLICANO, I.G., MCGAUGHEY, R.W., CAPCO, D.G. Activation of protein kinase $\mathrm{C}$ after fertilization is required for remodeling the mouse egg into the zygote. Molecular Reproduction and Development, v. 46, p. 587-601, 1997.

GALLICANO, I.G., SCHWARZ, S.M., MCGAUGHEY, R.W., et al. Protein kinase $\mathrm{C}$, a pivotal regulator of hamster egg activation, functions after elevation of intracellular free calcium. Developmental Biology, v. 156, p. 94-106, 1993.

GONÇALVES, P.B.D., GRAVES, C.N. Interaction between cAMP, Diacylglycerol and Ca-Calmodulin pathways in the regulation of cumulus expansion. Society for the Study of Reproduction, In: 25th Annual Meeting, Anais..., Raleigh, North Carolina, 1992.

GONÇALVES, P.B.D., HERNANDEZ, A.G., RUBIN, M.I.B., et al. Função da proteína quinase $\mathrm{C}$ na maturação nuclear em oócitos bovinos. Zootecnia, v. 32, p. 42, 1994.

HOMA, S.T. Neomycin, an inhibitor of phosphoinositide hydrolysis, inhibits the resumption of bovine oocyte spontaneous meiotic maturation. Journal of Experimental Zoology, v. 258, p. 95-103, 1991.

HOMA, S.T., WEBSTER, S.D., RUSSELL, R.K. Phospholipid turnover and ultrastructural correlates during spontaneous germinal vesicle breakdown of the bovine oocyte - effects of a cyclic-AMP phosphodiesterase inhibitor. Developmental Biology, v. 146, n. 2, p. 461-472, 1991.

KAUFMAN, M.L., HOMA, S.T. Defining a role for calcium in the resumption and progression of meiosis in the pig oocyte. Journal of Experimental Zoology, v. 265, n. 1, n. 69-76, 1993.

LEIBFRIED-RUTLEDGE, M.L., CRITSER, E.S., PARRISH, J.J., et al. In vitro maturation and fertilization of bovine. Theriogenology, v. 31, p. 61-74, 1989.

LEVESQUE, J.T., SIRARD, M.A. Effects of different kinases and phosphatases on nuclear and cytoplasmic maturation of bovine oocytes. Molecular Reproduction and Development, v. 42 , n. 1 , p. $114-121,1995$

LIU, Z., FOOTE, R.H. Development of IVM/IVF bovine embryos in KSOM, TCM-199 and MENEZO B2 with and without taurine. Biology of Reproduction, v. 50, n. 1 (Suppl.), 1994.

MILOVANOV, C., SIRARD, M.A. Manipulation of chromosome condensation by protein synthesis inhibitors and cyclic AMP during maturation of bovine oocytes. Theriogenology, v. 41, n. 4 , p. $819-827,1994$

MINAMI, N. Early embryonic-development under oviductal influence in-vitro. Animal Reproduction Science, v. 42, n. 14, p. 361-369, 1996 
PARRISH, J.J. Application of in vitro fertilization to domestic animals. In: Wassarman, P.M. Elements of Mammalian fertilization. Boca Raton: CRC press, 1991. cap. 3, p. 111132 .

ROSEHELLEKANT, T.A., BAVISTER, B.D. Roles of protein kinase $\mathrm{A}$ and $\mathrm{C}$ in spontaneous maturation and in forskolin or 3-isobutyl-1-methylxanthine maintained meiotic arrest of bovine oocytes. Molecular Reproduction and Development v. 44 , n. 2 , p. $241-249,1996$.

SCHOENBECK, R.A., PETERS, M.S., RICKORDS, L.F., $\boldsymbol{e}$ t al. Diacylglycerol-enhanced electrical activation of porcine oocytes matured in vitro. Theriogenology, v. 40, p. 257-266, 1993.

SIRARD, M.A., PARRISH, J.J., WARE, C.B., et al. The culture of bovine oocytes to obtain developmentally competent embryos. Biology of Reproduction, v. 39, p. 546-552, 1988
TATEMOTO, H., TERADA, T. Involvement of cyclic AMPdependent protein kinase in chromatin condensation before germinal vesicle breakdown in bovine oocytes. Animal Reproduction Science, v. 44, n. 2, p. 99-109, 1996.

TRIFARO, J.M., VITALE, M.L., RODRIGUEZ DEL CASTILLO, A. Cytoskeleton and molecular mechanisms in neurotransmitter release by neurosecretory cells. European Journal of Pharmacology, v. 225, p. 83-104, 1992.

VIGNOLA, A.G.H. Regulação da maturação nuclear e expansão das células do cumulus pelas proteínas quinase $A$ e C em oócitos bovinos. Santa Maria - RS. 84 p. Dissertação (Mestrado em Medicina Veterinária) - Curso de Pósgraduação em Medicina Veterinária, Universidade Federal de Santa Maria, 1995.

VIGNOLA, A.G.H., PRADO, A.D., VALENTE, A., $\boldsymbol{e} \boldsymbol{t} \boldsymbol{a l}$. Técnicas de coloração cromossômica para estágios específicos da maturação nuclear de oócitos bovinos. Ciência Rural, v 24 , n. 3 , p. $583-589,1994$

Ciência Rural, v. 29, n. 1, 1999. 